TechnoLEARN: An International Journal of Educational Technology

TechnoLEARN: 10(1\&2): 23-30, June \& December 2020

DOI: $10.30954 / 2231-4105.02 .2020 .4$

@2020 New Delhi Publishers. All rights reserved

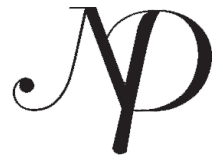

\title{
Instructional Design and Delivery System
}

\author{
Abraham Paul \\ Assistant Professor(ex), VIT University, Vellore-632014, India \\ Corresponding author: abraham.ab@gmail.com
}

Received: 12 Sept., 2020

Revised: 02 Nov., 2020

Accepted: 06 Dec., 2020

\begin{abstract}
Principles of learning are beliefs, tenets or axioms that guide the instructional process. Following are some general principles of learning. Teaching is not mere telling it is that which promotes learning and which guides, corrects, reinforces and evaluates learning. Active participation of the student in the teaching learning process is a prerequisite for learning. Similarities between instructional event and actual tasks in jobs lead to greater transfer of learning. Learners differ in the way in which they learn and the rate at which they learn. Learners are to be encouraged to continually evaluate past learning and assess their own needs for future learning.
\end{abstract}

Keywords: Adolescent students, Cognitive Characteristics, Motivation, Emotional Intelligence, Online Education

\section{Design System}

When designing instruction the following guidelines need to be borne in mind.

Accept that all students can learn. Learning is an active and continuous process. Active and sustained involvement of the learner makes him more involved for effective learning. Care must however be exercised to see that no training fads and gimmicks are introduced inappropriately.

\section{Psychological characteristics of Adolescent students}

Self-concept: Self-concept is the individual's perceptions of himself. Changes in the self-concept

How to cite this article: Paul, A. (2020). Instructional Design and Delivery System. TechnoLearn: An International Journal of Educational Technology, 10(1\&2): 23-30. 
¿p Paul

during adolescence are an important event. Strong self-confidence together with self-esteem builds up a healthy positive identity.

\section{Cognitive Characteristics and needs}

The development of knowledge and thinking process is known as cognitive development. Intellectual abilities come under cognitive process. Some functional abilities such as attending, perceiving, observing, remembering, imagining and using language also come under cognitive process. Cognitive development is sometimes described as extending the Intellectual horizon of the individual.

The cognitive developmental characteristics observed in the adolescence period are:

* Increased ability to generalize the facts

* Increased ability of understanding

* Increased ability to deal with abstraction

Development of memory and imagination

* Ability of problem solving

* Increased ability to communicate with other persons

Identification with conditions and characters in the larger world

- Ability to make decision

* Understanding of moral concepts

\section{Emotional Intelligence}

Fulfilment of emotional needs helps the individual to become emotionally mature. Further, emotional maturity contributes towards emotional intelligence (EI). EI refers to an assessment of affective domain skills, capabilities and competencies demands and influence a person's ability to succeed in coping with pressures. EI includes empathy, self-control, self-awareness, sensitivity to the feelings of others persistence and self- motivation.

The purpose of engineering/technology education is to make employable engineers for which colleges and educational institutions take suitable steps for the development of affective domain characteristics in students.

EI constitutes one of the important dimensions of the affective domain. Moderate to high level of EI empowers the individual in:

* Self-awareness

* Self- control

- Solving interpersonal conflicts 
Self-motivation

Decision making and

* Dealing deviant work place behaviour

The implications of various developments during adolescence have tremendous importance. It is the time when personality becomes increasingly differentiated and hierarchically organized. If the development needs are not properly fulfilled the result is maladjustment. The adolescent losses the sense of identity, the self-concept is derailed and acquisition of a set of values is impaired. The teachers can help the adolescent to meet their growing needs, cognitive, emotional and social.

\section{Motivation}

Motivation is the process by which individuals are impelled to seek a goal. It refers to factors which increase or decrease the vigour of activity. It is the process of arousing action, sustaining activities in progress, regulating and directing the pattern of activity. Motivation is a concept that explains why people behave as they do. Motivation is the key for learning and impetus to do well. In the teaching learning context motivation has the following functions: namely arousal, expectancy, incentive and disciplinary.

\section{Other functions of Motivation}

Energizes behaviour

Helps capture attention

* Helps develop interest

* Help acquire knowledge

* Help in character formation

Develops social qualities

* Regulates behaviour

\section{Causes for low levels of Motivation}

Difficulty in following classroom instruction

Disinterest in the course of study chosen

Inadequate facilities for study at home

* Influence of peer group

Teaching styles and strategies are not adequate

Inadequate laboratory and library facilities in the institutions 
CP Paul

Ambiguity of goals

Absence of proper guidance.

\section{Achievement Motivation}

* Concerned more with achieving success rather than avoiding failure give attention to the realistic possibilities of success.

* Sharply distinguish situations in which they have some control from situations where results largely depend upon chance and have definite preferences for involvement in situations where they have some control.

* Like to make independent judgements based on their own evaluation and experience rather than rely on the opinion of others.

* Show greater anticipation of the future and prefer larger rewards in the future to small rewards in the present.

- Set goals carefully, considering the possibilities of achieving them.

\section{Some tips for inducing achievement motivation in students}

* Inculcate creativity and Innovation of students

* Provide opportunities for active participation in the teaching learning process

Do not curb the initiative and enthusiasm of learners

* Students would like to have something which excites their intellectual curiosity

* Help students to set achievable goals

\section{Instructional Planning}

A good plan is imperative for effective teaching. Successful teachers are invariably good planners. The purpose of the lesson plan is to communicate. It is a guide to the teacher in helping students achieves intended learning outcomes.

The following factors are to be kept in mind while framing a lesson plan:

* What skills, facts, concepts, attitudes, and values should students learn?

Why should learners learn?

What should learners be able to do as a result of learning?

What entry behaviour students need to possess

What are the most appropriate sequence of topics and tasks?

What approaches/procedures and tools are necessary to test students? 


\section{FOUR PHASES OF A LESSON PLAN}

Introduction, development, consolidation and follow up.

\section{INSTRUCTIONAL METHODS}

1. Teacher Centered

* Lecture

Demonstration of the lecture.

2. Interactive

* Class Discussion

* Discussion groups

* Project method

* Peer coaching

3. Individualized

* Programmed instruction

* Modularized Instruction

Computer Assisted learning

* Distance education modes

4. Experiential learning

* Field visits/tips

- Laboratory work/workshop practices

* Role playing

* Games and simulations

\section{INSTRUCTIONAL STRATEGY}

Factors to consider while selecting Instructional Strategy

1. The objectives

Domain and level of learning

* Requirements of the task

2. The learners

* Experience/prior knowledge

* Special needs 
. $P$ Paul

3. Constraints of the Instructional situation

Class size

* Nature of the course

* Physical facilities/Institutional resource

* Time for instruction

\section{Student Evaluation}

Evaluation of student performance plays an important role in the teaching learning process. It reinforces student learning and provides feedback information to the teacher on the extent of learning achieved by the student through the various instructional procedures employed by him. The term evaluation may include either quantitative or qualitative description of student behaviour.

Evaluation $=$ Quantitative description of student behaviour + Value judgement

Evaluation $=$ Qualitative description of student behaviour + Value judgement

A sound evaluation program will include both measurement and non-measurement techniques, each to be used as appropriate.

\section{Uses of Student Evaluation}

It helps the teacher to:

* Assess how effective his/her instructional methods and strategies are

Detect students learning difficulties and provide remedial help

Identify individual student differences and suitably adapt his teaching strategies

Grade the students

* It helps the administrator to

Find the over- all effectiveness of the course

\section{Comprehensive Evaluation}

In technical education, an engineering student acquires a wide range of abilities in a variety of areas/subjects in cognitive, psychomotor and affective domains. The engineering students have not only to develop the knowledge, understanding and other higher order abilities with reference to the subject matter but also acquire needed practical skills and certain professional attitudes and character traits. Hence an evaluation scheme must be comprehensive to over all the three domains. The strategy and methods of assessment cannot be uniform and one must 
note that each domain or component demands a different kind of approach and procedure for assessment.

\section{Principles of Learning}

* Active participation by learners

* Repetitive practice is a must for learning

* Transfer of learning has positive effect

* Readiness a prerequisite for effective learning

* Learners to be encouraged constantly

* Knowledge of results enhance learning

* Learning process occurs through a wide variety of experiences

* A learner is responsible for his own learning

* Learner to be clear about objectives

* Continuous reward and feedback essential for effective learning

\section{Keys for writing: Instructional Objectives}

* State the objectives in terms of the learners

* Instructional objectives are not stated in terms of the teaching process or learning process

* Any one learning outcome essential in an objective statement

\section{Traits of good Teaching}

Being well prepared

Demonstrating comprehensive subject knowledge

* Motivating students

* Creating learning environment

* Being fair and reasonable

* Managing the learning process in the class

* Sincerely interested in the subject matter

* Enthusiastic in making the course effective

\section{Online Learning}

At present due to the Covid-19 pandemic most educational institutions have resorted to online education. 
D Paul

* Microsoft Teams app has replaced the role of a facilitator in this initiative. It is possible to schedule classes, deliver lectures and evaluate the students on this platform.

* Even prior to this online objective and subjective exams were conducted as part of online learning.

* In the days to come this is likely to cater to all category of learners.

\section{REFERENCES}

TISEL (TIST School of education and Leadership) FDP teaching material.

Principles of Management by Philip Kotler. 